\title{
A Mocidade Portuguesa Feminina e a formação culinária em Menina e Moça $(1947-1962)^{*}$
}

\author{
Isabel M. R. Mendes Drumond Braga** \\ Paulo Drumond Braga***
}

\section{Resumo}

A Mocidade Portuguesa Feminina, instituição criada em 1937 pelo Estado Novo, com o objectivo de inculcar nas crianças e nos jovens os ideais defendidos pelo regime, teve várias publicações, entre as quais a revista Menina e Moça, iniciada em 1947. Este artigo estuda o que à culinária diz respeito na referida publicação no lapso temporal que vai do seu início a 1962, ano em que a Mocidade Portuguesa Feminina comemorou 25 anos de existência. Estudam-se as informações, conselhos, advertências $e$ exortações ligadas à preparação, conservação e serviço das refeições, assim como as receitas, inseridas regularmente a partir de 1952 numa secção intitulada "Para o teu livro de receitas".

Palavras-chave: Portugal, Estado Novo, Mocidade Portuguesa Feminina, Culinária, Revista Menina e Moça.

\footnotetext{
Recebido para publicação em 15 de fevereiro de 2012, aceito em 10 de março de 2012.

** Professora do Departamento de História da Faculdade de Letras da Universidade de Lisboa. isabeldrumondbraga@hotmail.com

**** Professor da Escola Superior de Educação Almeida Garrett. drumondbraga@hotmail.com
}

cadernos pagu (39), julho-dezembro de 2012:201-226. 
A Mocidade Portuguesa Feminina e a formação culinária...

The Mocidade Portuguesa Feminina and the Culinary Development in Menina e Moça (1947 - 1962)

\begin{abstract}
The Mocidade Portuguesa Feminina, an institution created in 1937 by the New State, with the aim of inculcating in children and youth the ideals espoused by the regime, had several publications, including Menina e Moça, started in 1947. This article examines the culinary concerns in that publication in the years 1947 to 1962 (when the Mocidade Portuguesa Feminina celebrated 25 years of existence). We study the information, advice, warnings, and exhortations to the preparation, maintenance, and service of meals, as well as recipes, inserted regularly since 1952 in a section titled "To your cookbook".
\end{abstract}

Key Words: Portugal, New Estate (Estado Novo), Mocidade Portuguesa Feminina, Culinary, Menina e Moça Magazine. 
Não tenhas medo! Alguma vez hásde começar... Vamos, põe o avental, arregaça as mangas e... boa sorte! (Menina e Moça, n. ${ }^{\circ} 8,1947$ )

1. Em Portugal, durante o Estado Novo (1933-1974), não se descurou o papel das mulheres. Foi-lhes sendo concedido o direito de voto (1931- 1933, 1934, 1946 e 1968), ainda que de forma parcial - dependendo da idade, do facto de serem ou não chefes de família, das habilitações académicas e da contribuição predial paga (Pimentel, 2001:30-33) - e foram-lhes abertas as portas das duas câmaras parlamentares, a Assembleia Nacional e a Câmara Corporativa (1934) (Braga, 2011). Ao mesmo tempo, a ideologia difundida era a do regresso da mulher ao lar, privilegiando as facetas de esposa e mãe (Belo, Alão, Cabral, 1987: 263-279; Cova, Pinto, 1997; Alves, 2007; Máximo, 2007). Note-se que esta situação se foi gradualmente alterando no pós-guerra, com particular evidência nos anos 60 e 70, à medida que se generalizavam os casos de mulheres a trabalhar fora de casa (Pimentel, 2001:48-53; Aboim, 2011:92-98), no quadro de um cenário de aceleradas industrialização e urbanização do País (Oliveira, 1992:55-77; Martins, Amaral, Rollo, 1994; Telo, 1995).

Por decreto de 8 de Dezembro de 1937, do ministro da Educação Nacional, Carneiro Pacheco (1887-1957), foi criada a Mocidade Portuguesa Feminina, obrigatória para as crianças $e$ jovens entre os sete e os 14 anos e para as alunas que frequentassem o primeiro ciclo do liceu. Havia cinco escalões: dos sete aos 10 anos, as lusitas; dos 10 aos 14, as infantas; dos 14 aos 17, as vanguardistas e dos 17 aos 25 as lusas (Pimentel, 2001; Pimentel, 2007). A organização deveria educar a futura mulher nas perspectivas moral, cívica, física e social. A primeira e duradoura (1937-1968) comissária nacional da organização, Maria Guardiola (1895-1987), não deixou de notar que a toda a mulher cabia defender a trilogia cara ao Estado Novo: Deus, Pátria e Família (Pimentel, 2001:220). 
A Mocidade Portuguesa Feminina e a formação culinária...

Note-se que esta organização seguia de perto o modelo da sua congénere masculina, a Mocidade Portuguesa, criada pelo referido ministro em 1936. Ambas pretendiam inculcar nas crianças e nos jovens os ideais defendidos pelo regime. Também quer uma quer outra se inspiraram nas organizações de juventudes existentes na Itália de Mussolini e na Alemanha de Hitler (Kuin, 1993; Kuin, 1996; Kuin, 1999; Vieira, 2008). Tudo se enquadrava, afinal, numa profunda reforma do ensino que Carneiro Pacheco levou a cabo e que se destinava a criar um novo Português, católico, nacionalista e adepto do Estado Novo (Mónica, 1978; Carvalho, 1986: 753-778; Nóvoa, 1992: 458-460; Braga, 2010).

A revista Menina e Moça foi uma das várias publicações periódicas da Mocidade Portuguesa Feminina. O primeiro número datou de Maio de 1947 e resultou do desdobramento de uma anterior revista da organização, o Boletim da Mocidade Portuguesa Feminina, que se publicava desde 1939. Com essa divisão, além da Menina e Moça, nasceu o Boletim para Dirigentes (1947-1952 e 1963-1968). A organização tinha outras revistas, como por exemplo Lusitas (1943-1957), mais tarde chamada Fagulha (1958-1974), destinada a crianças; De Mãos Dadas (1961-1967), para alunas das escolas técnicas e Lavores e Trabalhos Manuais (1969-1974), para dar apoio às monitoras de tais áreas (Pimentel, 2001:337-338; Fidalgo, 2002:77-84).

A publicação que agora nos ocupa e interessa, Menina $e$ Moça, durou até 1974, ou seja, até ao final do Estado Novo. Considerava-se "a melhor revista para todas as raparigas". Segundo Marta Fidalgo, dirigia-se preferencialmente a um público urbano, das classes média e média-alta. Pensada inicialmente para alunas do ensino liceal, a partir de 1967 dedicou-se igualmente às frequentadoras de escolas técnicas (nessa data, extinguiu-se a revista De Mãos Dadas) e, eventualmente, terá procurado captar também jovens adultas, estudantes universitárias e alunas das Escolas do Magistério Primário, onde se formavam as professoras do ensino primário (Fidalgo, 2002:100-103). 
Cada número avulso custava, em 1947, $1 \$ 50$ para filiadas na Mocidade Portuguesa Feminina e $2 \$ 00$ para não filiadas. A assinatura anual era de $15 \$ 00$ no primeiro caso e de $20 \$ 00$ no segundo. Só em 1961 houve um encarecimento, passando os valores a ser, respectivamente: $2 \$ 00,3 \$ 00,25 \$ 00$ e 30\$00. Novo aumento ocorreu passados cinco anos: $3 \$ 00,3 \$ 50,30 \$ 00$ e $36 \$ 00$. De notar que a partir de 1970 a diferença passou a ser entre estudantes e não estudantes. As primeiras pagavam $5 \$ 00$ pelo número avulso e $50 \$ 00$ pela assinatura anual e as segundas $6 \$ 00$ e $60 \$ 00$, respectivamente. Em 1973, vésperas do fim do Estado Novo e, consequentemente, da Menina e Moça, os preços aumentaram de novo, mas deixou de haver discriminações: todas as leitoras pagavam $7 \$ 00$ ou $60 \$ 00$ (Fidalgo, 2002:94-95).

A directora da revista foi, de 1947 a 1972, Maria Joana Mendes Leal (1897-1976), importante figura feminina do Estado Novo, com cargos dentro e fora da Mocidade Portuguesa Feminina. Aqui, foi directora do primitivo Boletim, dos Serviços de Intercâmbio, Propaganda e Publicidade e dos Serviços de Formação de Dirigentes e Graduadas. Fora da organização, pertenceu à direcção da Obra das Mães para a Educação Nacional, foi vogal da Junta Nacional de Educação e, entre 1942 e 1957, teve assento na Câmara Corporativa. Solteira, como muitas outras mulheres da elite feminina do regime, católica empenhada, integrou organizações internacionais como a Obra de Protecção às Raparigas e foi autora de vários livros, entre os quais uma biografia do padre Cruz, que conheceu algum sucesso (Pimentel, 2001:422-423; Sousa, 2004; Sousa, 2005).

2. Esclarecidos os pressupostos da Mocidade Portuguesa Feminina e de um dos seus órgãos, a revista Menina e Moça, estudemos a actividade desta no que às questões culinárias se referiu. Por questões práticas, decidimos delimitar cronologicamente a nossa análise, escolhendo, por motivos óbvios, o início da publicação (1947) e terminando em 1962, ano em que a Mocidade Portuguesa Feminina comemorou 25 anos de 
A Mocidade Portuguesa Feminina e a formação culinária...

existência, o que se reflectiu, como seria de esperar, nas revistas da organização.

Ao longo das páginas da revista foram surgindo informações, conselhos, advertências e exortações ligadas à preparação, conservação e serviço das refeições bem como à ligação culinária e práticas caritativas. Exemplo paradigmático desta última questão era o chamado Folar de Páscoa, uma iniciativa anual da Mocidade Portuguesa Feminina que consistia em ir, durante aquela quadra, visitar crianças, "velhinhos", doentes e internados, levando quer folares (bolos) quer roupas e brinquedos (Pimentel, 2001:316-318). Se a opção fosse o folar, deveria o mesmo ser preparado por cada uma das filiadas $e$ entendido como um meio de santificar a quaresma. $\mathrm{O}$ enunciado apresentado era claro:

A Santa Igreja recomenda-nos durante este santo tempo a oração, a esmola e a mortificação. Se trabalhares na preparação do folar - no arranjo ou na confecção de roupas, brinquedos e outros mimos - com espírito de fé, o teu trabalho será oração. Poderás até oferecer a Deus esse trabalho (no momento de fazê-lo) por aqueles a quem se destina. A oração, como sabes, é o melhor meio de atrair a graça sobre as almas: de missionar. O folar dar-te-á também ocasião de praticares a esmola e a mortificação. Será um sacrifício agradável a Deus renunciares a qualquer coisa (por exemplo, uma ida ao cinema ou a compra de um objecto supérfluo) para com o produto da renúncia comprares material para o folar (Menina e Moça, 68, 1953).

Mesmo antes de haver uma secção específica de culinária, que nasceu em 1952, a revista ia inserindo, com alguma frequência, receitas. Por exemplo, em Setembro de 1947 surgem seis de ovos, com o título genérico "Os ovos. Grande recurso das donas de casa!" e com a explicação prévia: 
Nem sempre, no campo, há carne e peixe. Mas os ovos remediam a sua falta. Há tantos modos de os cozinhar! E são tão apetitosos e nutritivos os pratos que com eles se podem fazer! (Menina e Moça, 5, 1947).

Posteriormente, foram publicadas receitas de filetes de pescada (Menina e Moça, 12, 1948), torta de fiambre (Menina e Moça, 18, 1948), croquetes de carne, croquetes de camarão, ervilhas à inglesa, carne da grelha, fofos de batata, perdizes ensopadas (Menina e Moça, 25, 1949) e ainda omeletas diversas: com presunto, com camarão e parmentier, neste caso, três receitas (Menina e Moça, 30, 1949). Também se davam conselhos de ordem diversa, como por exemplo aconteceu em Setembro de 1948, quando se inseriu um artigo intitulado "No tempo da fruta". O mesmo servia, fundamentalmente, para que as jovens não comessem fruta verde e lavassem bem as peças se as ingerissem com casca. Ensinavamse ainda as formas de guardar fruta para consumir no inverno e de enfeitar mesas com fruteiros (Menina e Moça, 18, 1948).

Em textos não especificamente sobre culinária eram, em alguns casos, visíveis matérias afectas ao assunto que nos ocupa. Por exemplo, os "Contos da Carochinha", da autoria de Adriana Rodrigues, publicados ao longo dos anos, aproveitaram para abordar temáticas úteis à futura dona de casa: saber comprar peixe na praça (Menina e Moça, 2, 1947), preparar um piquenique (Menina e Moça, 11, 1948) ou confeccionar almôndegas (Menina e Moça, 24, 1949). É aqui muito visível que se pretende que a futura esposa e mãe seja uma excelente dona de casa, quer por saber adquirir géneros alimentares de qualidade quer por não ser excessivamente gastadora. De facto, no episódio da preparação do piquenique, conclui-se que era preferível confeccionar um pastelão de peixe do que comprar fiambre, mortadela e pastéis folhados. Efectivamente, se o primeiro acabava por ficar em $10 \$ 20$, só 250 gramas de mortadela custavam 11\$00 (Menina e Moça, 11, 1948). Por outro lado, embora não seja referida, a 
A Mocidade Portuguesa Feminina e a formação culinária...

preparação das almôndegas poderia ser feita com carne de segunda qualidade.

Num texto intitulado "A Mulher Ideal!", ao fazer um elenco das qualidades que supostamente o sexo masculino preferia no sexo feminino - o artigo refere ter sido feito a partir do testemunho de diversos rapazes, o que é duvidoso - deparamonos com a seguinte qualidade: "Capaz de dirigir um bom jantar $e$ até de o fazer, sendo preciso", mas sem incomodar o marido com minudências como "racionamento e dificuldades do mercado: a falta de peixe, o preço das batatas" (Menina e Moça, 9, 1948). Note-se, por um lado, que em 1948, o racionamento fazia parte do quotidiano das populações em resultado dos constrangimentos que se mantiveram mesmo após a II Guerra Mundial e, por outro, que fica claro a que público se destinava a revista, pois refere a possibilidade de a mulher confeccionar a refeição como algo excepcional.

Pouco tempo depois, a revista inseria uma matéria subordinada ao tema "Serás tu uma boa filha? Aplica a ti mesma este "test'". A oito perguntas, presumiam-se as respostas de vários tipos de rapariga: a egoísta, a preguiçosa, a vaidosa, a cabeça no ar e a boa filha. À pergunta "O que sabes tu do serviço da casa?", as respostas deveriam ser, por exemplo, para a vaidosa, "Cozinha? Que horror. E as unhas?!", para a cabeça no ar "Vê-se pelos livros de cozinha, à ultima hora" e, obviamente, para a boa filha, "Há segredos de êxito na cozinha, como no resto" (Menina e Moça, 10, 1948). Alguns anos mais tarde, Maria Estela Monteiro, em artigo intitulado "Sabes Equilibrar a tua Saúde?", a propósito dos cuidados com as refeições, fez notar a necessidade de se comer devagar e de não substituir uma refeição por uma merenda (Menina e Moça, 67, 1953). Em 1957, a revista passou a contar com uma página intitulada "Enciclopédia Familiar". Ao longo dos números, desfilaram, por ordem alfabética, entradas acerca de dezenas de produtos, com indicações básicas para que serviam, como se deviam utilizar, etc. Os géneros alimentares não foram esquecidos. 
Nem todas as participações eram assinadas. De qualquer modo, entre os que escreveram sobre alimentação e etiqueta à mesa aparecem colunas, páginas e secções cujo autor se dignou indicar o nome. Uma colaboração muito esporádica, em matérias alimentares, foi a de J. C., presumivelmente Jorgette Costa ${ }^{1}$ (Fidalgo, 2002:250), que escreveu sobre determinados produtos, tais como salmão, banana e sal. Estes artigos nunca continham receitas, as informações veiculadas eram de carácter histórico, biológico e nutricional, terminado sempre de forma edificante. Sobre o salmão: "quando algum dia o saboreares, não te esqueças de louvar a Deus por tão delicioso mimo das suas mãos criadoras" (Menina e Moça, 70, 1953). A banana motivou a seguinte interrogação: "quem não se decidirá a dar o melhor da sua preferência a esta fruta, deliciosamente perfumada que, por dom de Deus, e para delicia nossa, enriquece tantas terras de Portugal insular e ultramarino?" (Menina e Moça, 98, 1955). Finalmente, o sal permitiu exortar Deus e Portugal:

Bendito seja Deus pela terra portuguesa, tão pequenina mas tão rica de sal que o próprio Cristo enalteceu, ao simbolizar nele a virtude da preservação moral do mundo, recomenda aos seus apóstolos 'Vós sois o sal da terra' (Menina e Moça, 102, 1956).

Ou seja, após diversas informações de carácter generalista, terminava-se sempre com questões religiosas, aproveitando para louvar a Deus, neste caso, através da alimentação.

Em 1955, Armando Anjos assinou uma página intitulada "A Consoada". Dedicou-se a indicações acerca da prévia preparação da mesa e deu algumas sugestões:

\footnotetext{
1 Jorgette Gonçalves Costa exerceu vários cargos na Mocidade Portuguesa Feminia, nomeadamente delegada provincial de Trás-os-Montes e Alto Douro (1950-1951), auxiliar dos serviços centrais (1963) e directora do Centro de Estudos e Informação (1969-1974), além de redactora da revista De Mãos Dadas, igualmente da organização.
} 
A Mocidade Portuguesa Feminina e a formação culinária...

os pratos frios podem já ficar colocados sobre a mesa. O consommé pronto para ser rapidamente aquecido. Se a ceia constar só duma bebida quente, chocolate ou chá, que esta seja acompanhada por qualquer manjar diferenciado $e$ apetitoso: sanduíches de fois-gras ou fiambre, pãezinhos feitos em casa, brioches, e, sendo possível, a surpresa duma receita nova: um bolo que dê gosto (gosto ao paladar e ao coração). Daqui para diante, não há limites: podeis ir acrescentando peru, sonhos, etc. Mas, por hoje, ficaremos na ceia simples, modesta, e para ela vamos dar algumas receitas [tronco de Natal, pãezinhos e fois-gras] (Menina $e$ Moça, 100,1955).

A colaboração de Maria de Lourdes Modesto que, em 1960 já era famosa ${ }^{2}$, fez sentir-se uma única vez durante o período em

2 Maria de Lourdes Modesto, a mais conhecida gastrónoma portuguesa, que, contudo, prefere ser designada por gourmet hipermoderno, nasceu em Beja a 1 de Junho de 1930. De 1947 a 1949, frequentou, em Lisboa, o curso de Economia Doméstica, patrocinado pela Mocidade Portuguesa Feminina. Concluída a sua formação leccionou matérias de economia doméstica - cuja vertente prática da transmissão dos conhecimentos formativos das futuras donas de casa era um dos aspectos relevantes da educação feminina - nos cursos da Mocidade Portuguesa Feminina (onde chegou a ser inspectora dos serviços de culinária), do Liceu Feminino D. Filipe de Lencastre e do Liceu Francês Charles Lepierre, a par de outras actividades profissionais ligadas ao ensino de crianças deficientes em instituições como o Instituto Médico-Pedagógico Condessa de Rilvas e o Instituto António Aurélio da Costa Ferreira. De 1982 a 1988, leccionou Técnicas Culinárias na Escola Superior de Dietistas de Coimbra. O ambiente do Liceu Charles Lepierre, onde trabalhou durante oito anos, permitiu-lhe um alargamento de horizontes e a discussão frequente de questões de gastronomia com os colegas franceses. Aí, ao integrar o elenco de uma peça teatral de Molière, a qual foi objecto de uma reportagem televisiva, foi catapultada para a Rádio Televisão Portuguesa (RTP), a convite de Miguel de Araújo, responsável pelos programas culturais. A 15 de Maio de 1958, no ano seguinte à inauguração da televisão portuguesa, estreou-se com um programa em directo sobre alcachofras, então desconhecidas, em termos culinários, dos Portugueses. O facto de ter chupado uma folha da erva em pleno programa, causou algum espanto, pois ainda ninguém tinha sido filmado a comer. O programa, de periodicidade quinzenal, constituiu um sucesso, de tal modo que a saída da Televisão só ocorreu 12 anos mais tarde e por sua decisão. Voltará à RTP em 1978, 
realizando programas de prevenção alimentar de doenças cardiovasculares, no âmbito das actividades da Fundação Portuguesa de Cardiologia, da qual foi membro fundador. Em 1958, ganhou uma bolsa de estudo de um mês e foi para Paris estudar literatura contemporânea. Aí foi contactada pela multinacional de produtos alimentares Fima Lever com a qual trabalharia em Portugal durante 31 anos. Dirigiu o serviço de apoio ao consumidor e desempenhou funções nas áreas de publicidade e marketing daquela empresa. Entre as obras de Maria de Lourdes Modesto, a mais mediática autora de livros de cozinha portugueses, destaquem-se Grande Enciclopédia de Cozinha (1960), obra que começou por sair em fascículos, Receitas Escolhidas (1978) e, especialmente, Cozinha Tradicional Portuguesa (1982). Este livro, que começou por basear-se num concurso levado a cabo na RTP, em 1961, para recolher receitas tradicionais, e que até ao presente ultrapassou as 20 edições e os 400.000 exemplares vendidos, é constituído por texto ilustrado e organizado tendo em conta as culinárias das diferentes regiões do país, incluindo os arquipélagos da Madeira e dos Açores. Não obstante, não sendo, no início do século XX, a culinária entendida como algo particularmente importante, do ponto de vista da obtenção de notoriedade social, nota-se o recurso a anagramas e a pseudónimos para esconder o verdadeiro nome. Maria de Lourdes Modesto não escapou a essa tendência quando assinou textos de culinária como Francine Dupré. Basicamente eram obras nas quais se divulgavam marcas de produtos, como a margarina Vaqueiro, por exemplo. Entretanto abandonou este propósito, acompanhando o crescente interesse e popularidade que o público lhe foi dispensando. Colaborou em vários jornais, nomeadamente Independente, Diário de Notícias e Expresso on line. É membro de várias confrarias gastronómicas, do movimento Slow Food e da associação As Idades dos Sabores. Em 2004, foi agraciada com o grau de Comendador da Ordem de Mérito. Ao longo da sua vasta carreira recebeu diversos prémios, nomeadamente Reconnaissances 2006, da Academia Internacional de Gastronomia, Prémio de Literatura Gastronómica, da Academia Portuguesa de Gastronomia, Anuália e Gastronomia, da Revista de Vinhos. A 4 de Março de 1987, foi entrevistada pelo New York Times que a definiu como "Portugal's Julia Child", apesar de a sua congénere ter debutado apenas em 1962. A sua obra Cozinha Tradicional Portuguesa conheceu uma edição em inglês, em 1989. Crítica de alguns chefes e do seu mediatismo e de algumas cozinhas que considera não serem de autor, confessa-se admiradora de Vítor Sobral (um dos mais relevantes e premiados chefes portugueses da actualidade que acaba de inaugurar um restaurante em São Paulo) e da simplicidade das cozinhas tradicionais. Desconfia de quem não gosta de comer, defende que uma das razões para se gostar do Natal são os fritos, nomeadamente rabanadas, sonhos, brinhóis, bolinhos de jerimu, pastéis de grão, filhós tendidas e filhós de flor (basicamente doces confeccionados com ovos, açúcar, farinha, casca de laranja e, em alguns casos, abóbora, a par de algum vinho doce) e entende que, 
A Mocidade Portuguesa Feminina e a formação culinária...

estudo, através de uma página destinada a ensinar a fazer ovos de Páscoa. Depois de se deter em explicações básicas acerca do significado da Páscoa, a então professora passou para trabalhos do foro manual: esvaziar os ovos, pintá-los e, finalmente, recheálos, com chocolate. O texto foi acompanhado com imagens e termina com a seguinte afirmação: "se preparar muitos ovos de chocolate pode ainda confeccionar, com as claras e as gemas que lhe sobraram, o gigantesco ovo de Gargântua, o mais célebre de todos os comilões" (Menina e Moça, 148, 1960). Na colaboração seguinte, já de 1963, uma solicitação de uma leitora do Fundão motivou uma página dedicada a receitas de sorvetes e de gelados, as quais foram enviadas por Maria de Lourdes Modesto, a pedido da directora da revista, que escreveu "escolhidas por tão grande mestra, têm a garantia de ser óptimas" (Menina e Moça, 184, 1963). ${ }^{3}$

Em Setembro de 1952, no $\mathrm{n}^{\circ} 63$ de Menina e Moça, surgiu a secção "Para o Teu Livro de Receitas". Para o facto é dada uma explicação:

Pedem-nos as nossas filiadas para publicarmos receitas de cozinha, pois as dos livros de culinária são por vezes complicadas e, além disso, tem dificuldades na escolha... E pedem-nos, não receitas de alta cozinha, complicadas $e$ dispendiosas, mas receitas simples, que sirvam para qualquer refeição e não apenas para os grandes jantares. Pareceu-nos pois, que o mais útil seria começar... pelo princípio, e, assim, começaremos por algumas sopas. Teremos sempre o maior gosto em atender os pedidos das

na senda de muitos orientais, comer menos é um princípio saudável e de longevidade. Apesar de em entrevistas recentes ter declarado que não era fanática por cozinhar e não ter chegado à cozinha por vocação, em 1963, por ocasião dos 25 anos da Mocidade Portuguesa Feminina, em depoimento prestado à revista De Mãos Dadas, tornou claro que fora no curso de economia doméstica fornecido por aquela organização que descobrira a vocação que mudara a sua vida: a culinária (Braga, no prelo).

3 As receitas publicadas foram as de sorvete de café, sorvete de limão, gelado de chocolate, sorvete de ananás e gelado de pêssego. 
nossas leitoras; com a melhor boa vontade abriremos outras novas secções que nos forem sugeridas.

Assim, a secção teve início com receitas de sopa, a saber: caldo de carne, sopa de hortaliça, sopa de massa, sopa alemã, sopa nutritiva, sopa de tapioca, canja de galinha, sopa seca e sopa de cenouras. Esclarecia-se que as receitas seriam sempre destinadas a quatro ou cinco pessoas (Menina e Moça, 63, 1952). ${ }^{4}$ Note-se que, então, apesar da existência de pequenos livros de cozinha voltados para os tempos difíceis da II Guerra Mundial e do pós-guerra, a mais vendida obra de culinária era $O$ Livro de Pantagruel, da autoria de Rosa Berta Limpo, cuja primeira edição datou de 1946, com 1.500 receitas, e que, em 1952, já ia na $11 .^{a}$ edição, contando 3.000 receitas. $^{5}$

${ }^{4}$ Quando assim não era, indicava-se expressamente. Por exemplo, numa página intitulada "Bolos de Páscoa" de diversos países, referiu-se que as receitas estavam calculadas para oito pessoas (Menina e Moça, 81, 1954).

5 Berta Rosa Limpo (1894-1981) foi autora de O Livro de Pantagruel, cuja primeira edição datou de 1946. A obra tornou-se um clássico que, actualmente, conta com mais de 60 edições, as mais recentes com revisão e actualização dos filhos da autora: Maria Manuela Limpo Caetano (n. 1922) e o cineasta Jorge Brum do Canto (1910-1994). Trata-se uma obra ímpar no panorama editorial culinário português, contando originariamente com 1500 receitas, muitas delas de cunho vincadamente internacional. Ao contrário de muitas obras dos anos anteriores, este livro de culinária não foi escrito a pensar nos pobres e nos remediados, tónica que marcou as publicações em tempo de guerra e entre as duas guerras mundiais. No prefácio da primeira edição, a autora confessou a sua paixão pela culinária, o facto de ter feito uma primeira compilação de receitas de família em 1914, e o contacto directo com chefes cozinheiros franceses e italianos dos diferentes hotéis europeus por onde passava em digressão, quando era cantora lírica, que lhe forneceram receitas diversas. Não esqueçamos que também viveu em Milão durante algum tempo. Berta Rosa Limpo deu igualmente conta que todas as receitas haviam sido experimentadas e que todas davam bons resultados se fossem seguidas as instruções de forma criteriosa. A primeira edição de $O$ Livro de Pantagruel apresentou uma selecção de 1500 receitas, na $11 .^{\text {a }}$ edição o número de receitas duplicou e na $49 .^{\mathrm{a}}$ atingiu as 5000. Este aumento ficou a cargo da filha da autora, responsável pela obra. O aumento do número de receitas $e$ o aparecimento de algumas mais fáceis de preparar $e$ 
A Mocidade Portuguesa Feminina e a formação culinária...

A secção não surgia em todos os números, tendo estado totalmente ausente em 1954. Ainda assim, foram publicadas sugestões gastronómicas, em Abril e em Junho, aparecendo com a designação genérica de "Bolos da Páscoa", no primeiro caso (Menina e Moça, 81, 1954), e de "Receitas", no segundo (Menina e Moça, 84, 1954). Apenas em dois momentos - em Novembro de 1953 (Menina e Moça, 76, 1953) e em Maio de 1955 (Menina e Moça, 93, 1955) - a secção "Para o teu livro de receitas" foi assinada, concretamente por Maria Benedita, seguramente um pseudónimo, não nos tendo sido possível identificar a autora. As receitas eram acompanhadas de, pelo menos, uma imagem de um prato preparado e nunca das fases de preparação, com excepção da de ananás recheado com natas, com quatro imagens alusivas à elaboração (Menina e Moça, 123,1957).

A secção não suscitou cuidados especiais nem qualquer tipo de rigor. Nunca houve a preocupação de apresentar ementas completas e nem sempre as indicações nas receitas primaram pela precisão. Expressões como "uma porção de vitela bem magra" ou um "pouco de miolo de pão" (Menina e Moça, 102, 1956) foram comuns. Fornecia-se informação que pressupunha a existência de conhecimentos prévios adquiridos ou em casa ou nas aulas de culinária. Por exemplo, ao indicar a receita de camarões em croquetes, elucidou-se: "depois de cozidos os camarões, faz-se um molho branco com leite, ao qual se junta duas gemas de ovos e os camarões. Deixa-se esfriar e embrulham-se os croquetes como é costume" (Menina e Moça, 74, 1953). Aqui nem a receita de molho branco foi objecto de indicação nem o modo de preparar a iguaria.

menos onerosas resultou da consciência do alargamento do público leitor da obra e foi objecto de discussão familiar. Volvidos mais de 60 anos, O Livro de Pantagruel, com uma apresentação sóbria e escrita muito clara, continua actual, sendo a obra de cozinha com mais edições e maior tiragem em Portugal. Embora tenha nascido da criatividade de Berta Rosa Limpo, tornou-se um livro de família e um ex-libris da mesa portuguesa. Hoje em dia, todos os exemplares são numerados e assinados pelo neto da Autora. 
A partir de Maio de 1956, com charlotte de amêndoas, brioche, pudim estupendo, pudim de laranja, bolo para chá, queijinhos do céu e palitos italianos, pela primeira vez as receitas têm duas secções: os ingredientes e o modo de preparação (Menina e Moça, 105, 1956). Mas, pontualmente, verificaram-se retrocessos e voltou-se ao esquema anterior, o que pode indiciar a colaboração de autores diferentes nas páginas sob o mesmo título.

Em alguns momentos verificaram-se preocupações no sentido de fornecer receitas que coincidissem com a sazonalidade de determinados produtos para um melhor aproveitamento das potencialidades culinárias e económicas a favor de uma boa economia doméstica. São exemplos o doce de morango, em Maio de 1957 (Menina e Moça 117,1957); os gelados no volume de Julho e Agosto (Menina e Moça, 119,1957) e as compotas de pêra, pêssego, maçã, mousse de maçã e geleia de maçã, em Setembro do mesmo ano (Menina e Moça, 120, 1957).

A Páscoa e o Natal eram quadras que, ao longo dos anos, foram quase sempre merecendo atenção especial em todas as matérias, incluindo as de culinária. Por exemplo, no Natal de 1953, para a ceia, aconselhou-se a escolha de uma receita (pudim, peras, bananas ou maçãs) a que se juntasse rum e se flamejasse, sendo salientado o efeito cénico da acção (Menina e Moça, 77, 1953). Para a Páscoa do ano seguinte, sob o título "Bolos de Páscoa", publicaram-se receitas de exemplares de diversas origens: Alemanha, Áustria, Bélgica, Chile, Inglaterra e Polónia (Menina e Moça, 81, 1954).

Em Março de 1955, portanto longe do Natal, no meio de receitas de sopas e de peixes encontra-se uma referência ao tradicional peru, concluindo-se a exposição com uma receita. Previamente, começou por ensinar-se como se deve tratar a ave, caso não se tivesse acesso a exemplares criados no Alentejo:

24 dias antes de o matar abre-se-lhe o bico e mete-se-lhe dentro uma noz com casca. Com as mãos ajuda-se a fazê-la passar no pescoço. Isto faz-se durante 24 dias. Todos os 
A Mocidade Portuguesa Feminina e a formação culinária...

dias se dá uma noz a mais. No último come 24 nozes. No dia seguinte mata-se. Dá um esplêndido paladar (Menina e Moça, 91, 1955).

A crueldade e a aberração do procedimento destacam-se na exposição, mostrando uma nula preocupação com o sofrimento dos animais, nomeadamente os que destinavam à alimentação humana, situação ainda hoje não totalmente ultrapassada, apesar dos esforços verificados em anos mais recentes (Costa, 1998; DeMello, 2011).

Se bem que logo da primeira vez que foi publicada a secção "Para o teu livro de receitas" tenha havido uma preocupação temática, depois abandonou-se a prática, apresentando-se receitas muito diversas por números. Mas, em 1959, voltou a haver receitas temáticas. Em Janeiro, publicaram-se sete de ovos: ovos quentes, outra receita de ovos quentes, ovos estrelados, omeleta, ovos recheados com presunto, ovos mexidos com carne e ovos recheados (Menina e Moça, 135, 1959). No mês seguinte, as atenções recaíram nas laranjas: bolos de laranjas, doce de laranja, laranja cristalizada, dois pudins gelados de laranja, filhós de laranja e pudim de laranja (Menina e Moça, 136, 1959). Em Abril, sob os auspícios de "Uma chávena de chá" deram-se conselhos acerca do modo de receber convidados e de apresentar a mesa, ensinou-se a fazer chá e forneceram-se receitas de bolos para o acompanhar: cacos, misos, bolos fintos, torta de fruta, bolo delicioso, bolo simples, bolachas de nata, broinhas de coco e bolinhos de manteiga (Menina e Moça, 138, 1959). O número de Julho e Agosto foi dedicado a receitas de todos os dias ${ }^{6}$ : ervilhas guisadas, favas com paio e morcela, bacalhau com tomates, linguado com recheio de camarões e filetes de polvo (Menina $e$

6 Berta Rosa Limpo, em Maio de 1946, numa página dedicada a esclarecer as leitoras da revista Modas e Bordados, fez saber que em O Livro de Pantagruel não constava a receita de ervilhas guisadas: "não inclui essa receita por ser um prato bastante vulgar e do conhecimento de quase todas as cozinheiras" (Modas e Bordados, 1946). 
Moça, 140, 1959). Em Setembro pontuaram os sorvetes: sorvete de limão, sorvete de amêndoas e sorvete de leite, ao mesmo tempo que se iniciou uma coluna intitulada "Pequenos Segredos de Culinária", na qual se podem ler instruções para evitar que o leite talhe ou que a maionese deslace, por exemplo (Menina e Moça, 141,1959). No mês seguinte, a rubrica foi dedicada ao aproveitamento de claras de ovos com receitas como: pudim de claras, bolas de neve, mousse de chocolate, mousse de frutas, merengues, dama branca, bolo mousse, bolo de prata e farófias (Menina e Moça, 142, 1959). Em Maio de 1962, investiu-se no morango: com vinho, em sorvete, com chantilly, doce, mousse, compota, torta e pudim (Menina e Moça, 171, Maio de 1962). Em Outubro do mesmo ano, houve lugar a receitas a partir de maçã: charlotte e compota (Menina e Moça, 175, 1962). Nos anos seguintes, esta prática continuará, embora com excepções.

Algo com interesse que se relaciona com questões temáticas, mas de um outro âmbito, refere-se às receitas que surgiram em Fevereiro de 1962: arroz chow-chow (Macau), pato à moda de Cabo Verde, frango à cafreal (oriundo de Moçambique, ainda que a revista não o refira) e salada de ananás (Açores)(Menina e Moça, 168, 1962). A explicação é simples: no ano anterior, em Fevereiro, tinha começado a guerra colonial em Angola, em Julho, haviam ocorridos ataques a Portugueses na Guiné e, em Dezembro, derase a perda do Estado Português da Índia. A guerra seria estendida à Guiné (1963) e a Moçambique (1964). O governo de Lisboa manteve-se, até 1974, renitente, recusando-se a dar a independência às suas colónias, mas a ofensiva internacional foi sendo cada vez mais forte (Pinto, 2000). O aparecimento de receitas oriundas de partes diversas do Ultramar numa publicação de 1962 não era ingénuo. Portugal queria mostrar ao Mundo que começava no Minho e acabava em Timor e que essa situação não se iria alterar. Esta foi apenas uma das contribuições da Menina e Moça relativamente a esta grave questão política (Fidalgo, 2002: 177-180, 203-221; Azevedo, 2011). 
A Mocidade Portuguesa Feminina e a formação culinária...

Analisemos as receitas publicadas na secção "Para o teu Livro de Receitas", ao longo do período em estudo. Como se pode ver pelo quadro, e como já referimos, com excepção do ano de 1954, todos registaram algumas receitas, embora em quantidades muito diversificadas oscilando entre cinco, em 1955 e em 1960, e 53, em 1953. As 208 receitas apresentadas contemplaram, por ordem decrescente, os doces, os quais representaram $36,5 \%$ do total. Seguiram-se os pratos de peixe, com 13,9\%; em terceiro lugar, temos os de carne e os de legumes, com $10,6 \%$ cada. Ovos, sopas e aves também surgiram, com percentagens de $7,2 \%, 5,7 \%$ e $5,2 \%$, respectivamente. No apartado outros, $10 \%$ do total das receitas, incluímos acepipes, arroz (alegre, chow-chow e à valenciana), massas (tenra, cozida, de empadão $e$ para tortas de fruta), molhos (de entre outros, branco, alemão, holandês, inglês, de tomate, de ovo cozido, vilão) e pontos de açúcar. Os três últimos transversais a diversas receitas.

\section{Quadro 1}

Tipologia das Receitas apresentadas na Secção "Para o teu Livro de Receitas"

\begin{tabular}{|c|c|c|c|c|c|c|c|c|c|}
\hline Anos & Carne & Aves & Peixe & Legumes & Ovos & Sopas & Doces & Outros & Total \\
\hline 1952 & 8 & - & - & 1 & 2 & 10 & 1 & - & 22 \\
\hline 1953 & 10 & 6 & 9 & 12 & 4 & - & - & 12 & 53 \\
\hline 1954 & - & - & - & - & - & - & - & - & 0 \\
\hline 1955 & - & - & 1 & 1 & 1 & 1 & 1 & - & 5 \\
\hline 1956 & 3 & - & 2 & 2 & & & 10 & 5 & 22 \\
\hline 1957 & 1 & 1 & 5 & 4 & 1 & 1 & 6 & 1 & 20 \\
\hline 1958 & - & - & 1 & - & - & - & 12 & - & 13 \\
\hline 1959 & - & - & 3 & 2 & 7 & - & 19 & - & 31 \\
\hline 1960 & - & 1 & 3 & - & - & - & - & 1 & 5 \\
\hline 1961 & - & 1 & 5 & - & - & - & 10 & 1 & 17 \\
\hline 1962 & - & 2 & - & - & - & - & 17 & 1 & 20 \\
\hline Total & 22 & 11 & 29 & 22 & 15 & 12 & 76 & 21 & 208 \\
\hline
\end{tabular}


Uma análise mais fina permite identificar melhor os ingredientes e caracterizar os pratos. Em primeiro lugar, os de peixe, com predomínio do bacalhau, com sete receitas, seguindose o linguado com quatro: um peixe seco e barato e um peixe de qualidade e preço elevado. A pescada, igualmente um peixe nobre $e$, com parcas referências, peixes populares como enguia, peixeespada e sardinha. Lugar ainda para ameijoa, camarão, lula, ostra e polvo. No reino da carne, pontuaram pratos de vaca e vitela (com 10 referências), seguindo-se a grande distância, porco, coelho, carneiro, enchidos e vísceras. Nas aves, galinhas e perus ficaram empatados, seguindo-se receitas de pato, perdiz e frango. Note-se que diversas preparações indicaram carne, aves e peixe não especificados. Saliente-se que algumas receitas foram pensadas para aproveitar restos. Antes referimos os aproveitamentos de claras. Mas houve mais: por duas vezes, quando foram publicadas receitas de croquetes de carne, especificou-se a utilização de "restos da carne assada" (Menina e Moça, 25, 1949; Menina e Moça, 64, Outubro de 1952). O mesmo aconteceu com as receitas de lombo fingido, carne à moda burguesa (Menina e Moça, 68, 1953), croquetes e pudim de peixe (Menina e Moça, 157, 1961). Tudo isto estava de acordo com um dos princípios que o Estado Novo procurava inculcar nas gentes: "poupar, reutilizar, do 'velho virar novo', evitar o desperdício" (Vaquinhas, Guimarães, 2011:212-213). Os legumes foram diversificados: bróculo, cenoura, couve, ervilha, fava, nabo $e$ tomate. Faz notar-se a ausência de pasta, cuja maior entusiasta e divulgadora em Portugal será Berta Rosa Limpo. O arroz foi residual, com apenas três menções. Entre os doces foi claro o predomínio de doces de colher - com 40 referências, entre bavaroise, charlotte, mousse, pudim e sorvete - seguindo-se os bolos $e$ bolinhos $e$, finalmente, as geleias, compotas $e$ frutas cristalizadas.

Apesar de ter sido criado o apartado "Para o teu livro de receitas", a Menina e Moça continuou, uma vez ou outra, a inserir receitas fora da referida secção. Por exemplo, em Outubro de 
A Mocidade Portuguesa Feminina e a formação culinária...

1952 apareceram, com a designação genérica de "Receitas", cozido à portuguesa, croquetes de carne, pudim de carne, carne estufada, carne à inglesa, rosbife e carne na grelha (Menina e Moça, 64, 1952). O mesmo aconteceu em Junho de 1954, quando surgiram bolo delicioso, pudim de inverno, leite-creme, creme de ananás, maçãs com creme, maçãs escondidas, pastéis de coco, delícias de Baco e creme de castanhas (Menina e Moça, 83, 1954). Em Julho-Agosto de 1961, sob o título de "Pique-nique", a revista deu as receitas de costelas fingidas, pãezinhos com chouriço, sanduíches de atum e pickles (Menina e Moça, 162, 1961).

Um outro aspecto refere-se à existência de produtos mais caros $e$ de produtos mais baratos, podendo estes substituir aqueles. No número de Natal de 1961, indicou-se que a galinha era uma perfeita substituta do peru, esclarecendo-se: "Os perus estão caros. Nem todos os orçamentos domésticos comportam essa despesa". Assim, sugeria-se um prato de galinha recheada (Menina e Moça, 166, 1961).

As receitas nunca indicaram marcas, excepção para as bolachas de Maizena - ou seja, confeccionadas com farinha de amido de milho, da mesma marca (Menina e Moça, 43, 1950; 160, 1961) - e a farinha Salozema, referida numa de pastéis de batata (Menina e Moça, 74, 1953).

Houve ainda, esporadicamente, a preocupação em dar conselhos práticos às donas de casa. Em Fevereiro de 1950, num artigo intitulado "O Lar. ABC da dona de Casa", as leitoras foram esclarecidas de aspectos tão diversos como a limpeza de utensílios de cobre, a forma de conseguir desamarrotar roupa e alguns truques culinários. Neste último caso, podemos ler, por exemplo, que "a carne e o peixe conservam-se embrulhando-os num pano molhado em vinagre"; "as claras de ovo batidas ficam mais duras juntando-lhes uma gota de limão"; "a carne assada, para se aquecer, mete-se em banho-maria" (Menina e Moça, 34, 1950).

Foram raras as indicações acerca da etiqueta à mesa. Mesmo assim, por exemplo, em Março de 1960, foi publicada uma página destinada a ensinar a por a mesa, com imagens, de mesas 
postas e desenhos/esquemas de guardanapos sobre o prato, sopa já servida, depois de retirado o prato da sopa, serviço de salada, serviço de sobremesa e depois de retirado o lavabo (Menina $e$ Moça, 147, 1960), correspondendo às diversas fases de uma refeição. Recordemos que os manuais de etiqueta asseguravam este tipo de necessidades quer na época quer no passado (Braga, Braga, 2004:9-42). Em Outubro do mesmo ano, a apresentação de pratos com imagens acompanhou duas receitas: pudim de legumes e pão de Itália (Menina e Moça, 153, 1960). Antes, em Setembro, numa página sem qualquer receita, dedicada aos frutos frescos e aos secos, na qual se deram informações acerca do modo de os descascar e preparar, também se referiu o serviço (Menina e Moça, 152, 1960). Em Novembro de 1961, davam-se vários conselhos sobre a forma de estar à mesa, por exemplo, "antes de levar o copo à boca, limpam-se os lábios. É muito feio ver um copo enodoado" ou "se houver um sacerdote à mesa, devemos aguardar, antes de nos sentar, que ele reze o benedicte" (Menina e Moça, 165, 1961). ${ }^{7}$

7 De notar que outras publicações da Mocidade Portuguesa Feminina se referiam à culinária. Recorde-se o Suplemento Auxiliar ao Programa de Culinária, aparecido em 1969. Nele, alude-se a dois tipos de mulheres, as que faziam as tarefas domésticas e as que as superintendiam. Por exemplo, logo no início da brochura, pode ler-se: "mesmo dispondo de uma cozinheira e, embora o emprego (se o tiver) lhe ocupe grande parte do seu tempo, não deve [a mulher] deixar de aproveitar alguns momentos diários para dar um pouco de assistência à cozinha" (Suplemento Auxiliar, 1969:5). Seguem-se informações acerca das condições físicas das cozinhas, dos materiais para preparar os alimentos e higienizar o equipamento, além da explicação técnica dos termos cozedura, guisado, estufado, assado, grelhado, fritura, salteado e pontos de açúcar, tendo em conta que alimentos poderiam sofrer determinadas operações $e$ como essas mesmas operações deveriam ser levadas a efeito. Não podemos esquecer que as alunas tinham, entre as actividades circum-escolares, do final do Estado Novo, aulas teóricas sobre economia doméstica, governo da casa e alimentação e aulas práticas de culinária, durante as quais se procedia à elaboração de um prato (não particularmente requintado) e, enquanto aquele cozia, era ditada a receita, lavada a louça e arrumada a cozinha. No final, eram dadas indicações acerca do modo de apresentar o prato, finalizando a aula prática com a prova. As receitas nem sempre indicam separadamente 
A Mocidade Portuguesa Feminina e a formação culinária...

3. A Mocidade Portuguesa Feminina, criada à imagem da sua congénere masculina, serviu os mesmos propósitos mas através de meios diferentes, o que se justificou cabalmente se atendermos ao cultivo das diferenças de género fomentadas por uma educação diferenciada para homens e mulheres, de acordo com a ideologia de então. $\mathrm{O}$ ensino da culinária visava formar as futuras esposas dos grupos com menos meios no desempenho de uma das virtudes femininas: ser boa dona de casa, preparando refeições gostosas e baratas para agradar ao marido através da mesa e para poupar evidenciando a faceta de boa administradora do lar. As que podiam ter criada deveriam conhecer o serviço doméstico para o supervisionar. Os ideais do Estado Novo - Deus, Pátria e Família - seriam cabalmente cumpridos por homens e por mulheres, cada um dando o seu contributo proporcional ao sexo, à idade e à posição social, mas sempre ao serviço da causa maior, a ideologia do regime que tudo formatava visando o conformismo e a perpetuação do status quo vigente.

A revista Menina e Moça fez eco dos ideais subjacentes à educação feminina e contribuiu, a seu modo, durante décadas, para que as jovens se formassem alicerçando os seus comportamentos de forma a obedecerem, pouparem, ajudarem o próximo, serem discretas, trabalhadoras, fomentarem todas as actividades subjacentes à boa administração do lar, à educação dos filhos e a estarem ao serviço dos maridos. Tudo isto guiado pelo amor e temor a Deus e à Igreja. Na verdade, boa parte destes comportamentos nada apresentaram de novo, foram resultado de seculares discussões acerca da educação feminina, cujos primeiros cultores nos apareceram durante o Renascimento, se intensificaram no período do Iluminismo e se continuaram a

ingredientes e processos de execução, as quantidades e os tipos de carne ficaram quase sempre omissas tal como os tempos de cozedura e os tipos de fornos. De notar ainda que a maior parte das receitas de carne era preparada com aquele ingrediente passado, o que, naturalmente, pressupõe a possibilidade de aproveitamento de restos (Braga, 2008:123-124). 
manifestar, de forma quase imutável, ao longo de boa parte do século XX.

A carga profundamente política desta educação feminina que, curiosamente, pretendia dar origem a uma mulher alheia à política - apesar da existência de algumas deputadas, procuradoras à Câmara Corporativa e com cargos de chefia na Mocidade Portuguesa Feminina - desejava que a mesma se mantivesse na esfera doméstica, numa época em que muitas já trabalhavam fora de casa - um mal menor - quando os seus cônjuges não conseguiam sozinhos suprir as necessidades do agregado familiar, chegou, como vimos no início, à publicação de revistas formativas e informativas para as meninas dos diferentes grupos etários. Nada escapava ao controlo que o regime praticava $e$ às ideias que pretendia inculcar nos homens e nas mulheres de então. A culinária, a seu modo, era uma pequena peça de um complexo jogo de valores que todos jogavam. As receitas simples, económicas e muitas dadas ao aproveitamento dos sobejos de pratos anteriores, poderiam parecer, a olhos não familiarizados com o contexto político, inocentes mas não o foram. Estiveram sempre, em alguns casos ostensivamente, ao serviço da ideologia do regime.

\section{Referências bibliográficas}

ABOIM, Sofia. Vidas Conjugais. Do Institucionalismo ao Elogio da Relação. In: MATTOSO, José. (dir.). História da Vida Privada em Portugal, vol. 4, Os Nossos Dias. Lisboa, Círculo de Leitores, Temas \& Debates, 2011, pp.80-111.

Alves, Silvina Maria Cardoso da Silva Resende Pinto. A Educação e os Manuais Escolares do Ensino Primário (1910-1851). Porto, Dissertação de Mestrado em História da Educação, Faculdade de Letras da Universidade do Porto, 2007.

Azevedo, Ana Carina. Discurso Colonial do Estado Novo na Imprensa das Organizações Femininas do Regime: a Menina e Moça e a Presença. Ler História (60), Lisboa, 2011, pp.115-131. 
A Mocidade Portuguesa Feminina e a formação culinária...

Belo, Maria; Alão, Ana Paula; CABRAl, Iolanda Neves. O Estado Novo e as Mulheres. In: O Estado Novo: Das Origens ao Fim da Autarcia (1926-1959), vol. 2, Lisboa, Fragmentos, 1987, pp.263-279.

BragA, Isabel M. R. Mendes Drumond. Culinária no Feminino: Os Primeiros Livros de Receitas Escritos por Portuguesas, Caderno Espaço Feminino (19,1), Uberlândia, 2008, pp.117-141. Também disponível em: <http://www.seer.ufu.br/index.php/neguem/index > .

BRAGA, Isabel M. R. Mendes Drumond. Maria de Lourdes Modesto. In: DidiER, Béatrice; CAlle-GrubER, Mireille e FOUQUE, Antoinette. (dirs). Le Dictionnaire des Créatrices. Paris, Editions Des Femmes.

Braga, Isabel M. R. Mendes Drumond; BragA, Paulo Drumond. Civilidades. Por quê? Para quê? Para quem? In: CARVALHO, Maria Amália Vaz de. Arte de Viver na Sociedade, estudo e actualização do texto de Isabel M. R. Mendes Drumond Braga e Paulo Drumond Braga. Sintra, Colares Editora, 2004, pp.9-42.

BRAGA, Paulo Drumond. A Educação em debate na Assembleia Nacional: o contributo das mulheres deputadas (1945-1957). E-Paper 1, Lisboa, 2011. Disponível em $<\mathrm{http} /$ www.eseag.pt/index.php/investigacao/centro-de-investigacaoe-publicacoes/e-papers $>$.

Os ministros da Educação Nacional (1936-1974). Sociologia de uma função. Revista Lusófona de Educação (16), Lisboa, 2010, pp.23-38.

Carvalho, Rómulo de. História do Ensino em Portugal. Desde a Fundação da Nacionalidade até ao fim do Regime de SalazarCaetano. Lisboa, Fundação Calouste Gulbenkian, 1986.

CostA, António Pereira da. Dos Animais (O Direito e os Direitos). Coimbra, Coimbra Editora, 1998.

COVA, Anne; PINTO, António Costa, O Salazarismo e as Mulheres. Uma Abordagem Comparativa. Penélope (17), Lisboa, 1997, pp.71-84.

Demello, Margo. The Presente and Future of Animal Domestication. In: KALOF, Linda e RESL, Brigitte. A Cultural History of Animals, vol. 6, Oxford, Nova York, Berg, 2011, pp.67-94. 
FIDALGO, Marta Véstia. Menina e Moça: Um Ideal de Formação Feminina (1960-1970). Lisboa, Organizações Não Governamentais do Conselho Consultivo da Comissão para a Igualdade e para os Direitos das Mulheres, 2002.

KuIN, Simon. A Mocidade Portuguesa nos anos 30: Anteprojectos e Instauração de uma Organização Paramilitar da Juventude. Análise Social (122), Lisboa, 1993, pp.555-580.

. Mocidade Portuguesa. In: RosAS, Fernando e BRITO, J. M. Brandão de (dir.). Dicionário de História do Estado Novo, vol. 2, Venda Nova, Bertrand, 1996, pp.607-609.

- Mocidade Portuguesa. In: BARRETO, António e MóNICA, Maria Filomena (dir.). Dicionário de História de Portugal. Suplemento, vol. 8, Porto, Figueirinhas, 1999, pp.499-501.

MARTINS, Fernando; AmARAL, Luciano; Rollo, Maria Fernanda. As 'mudanças invisíveis' do pós-guerra. In: MATTOSO, José (dir.). História de Portugal, vol. 7, Lisboa, Estampa, 1994, pp.419-485.

MÁXIMO, Maria Elsa dos Santos Costa. A Política Educativa no Estado Novo em Relação à Mulher, no Tempo do Ministro António Faria Carneiro Pacheco (1936-1940): Contributo para a História do Género em Portugal. Dissertação de Mestrado em Didáctica da História, Faculdade de Letras da Universidade de Lisboa, 2007.

MÓNICA, Maria Filomena. Educação e Sociedade no Portugal de Salazar. A Escola Primária Salazarista (1926-1939). Lisboa, Gabinete de Investigações Sociais, Presença, 1978.

NóvOA, António. A 'Educação Nacional'. In: SERRÃO, Joel e MARQUES, A. H. de Oliveira. (dir.) Nova História de Portugal, vol. 12, Lisboa, Presença, 1992, pp.454-519.

OliveIRA, César de. A evolução política. In: SERRÃo, Joel e MARQUES, A. H. de Oliveira. (dir.) Nova História de Portugal, vol. 12, Lisboa, Presença, 1992, pp.21-85.

PIMENTEL, Irene Flunser. História das Organizações Femininas do Estado Novo. Lisboa, Temas e Debates, 2001. 
A Mocidade Portuguesa Feminina e a formação culinária... Livros, 2007.

. Mocidade Portuguesa Feminina. Lisboa, A Esfera dos

PINTO, António Costa. A Guerra Colonial e o Fim do Império Português. In: Bethencourt, Francisco e CHAUdHuRI, Kirti. (dir.) História da Expansão Portuguesa, vol. 5, Lisboa, Temas e Debates, 2000, pp.65-98.

SouSA, António Ferreira de; LEAL, Maria Joana Moreira Mendes. In: CASTRO, Zília Osório de e ESTEVES, João. (dir.) Dicionário no Feminino. Lisboa, Horizonte, 2005, pp.697-700.

SouSA, Maria Reynolds de; LEAL, Maria Joana Moreira Mendes. In: Manuel Braga da e António Costa. (dir.) Dicionário Biográfico Parlamentar. 1935-1974. vol. 1, Lisboa, Universidade de Lisboa, Instituto de Ciências Sociais, Assembleia da República, 2004, pp.802-803.

TELO, António José. Portugal, 1958-1974: sociedade em mudança. In: MedinA, João. (dir.) História de Portugal. Dos Tempos Pré-Históricos aos nossos Dias, vol. 113, tomo2. Amadora, Ediclube, 1995, pp.287-315.

VAquinHAS, Irene, GuIMARÃES, Maria Alice Pinto. Economia Doméstica e Governo do Lar. Os Saberes Domésticos e as Funções da Dona de Casa. In: MATTOSO, José. (dir.) História da Vida Privada em Portugal, vol. 3 (A Época Contemporânea). Lisboa, Círculo de Leitores, Temas \& Debates, 2011, pp.194-221.

VIEIRA, Joaquim. Mocidade Portuguesa. Lisboa, AEsfera dos Livros, 2008.

Fontes

Menina e Moça. Lisboa, 1947-1962.

Modas e Bordados. Lisboa, 1946.

Suplemento Auxiliar do Programa de Culinária. Lisboa, Mocidade Portuguesa Feminina, 1969. 